\title{
Corrigenda: Cherax warsamsonicus, a new species of crayfish from the Kepala Burung (Vogelkop) peninsula in West Papua, Indonesia (Crustacea, Decapoda, Parastacidae) ZooKeys 660: 151-167. https://doi.org//0.3897/zookeys.660.11847
}

\author{
Christian Lukhaup', Rury Eprilurahman², Thomas von Rintelen ${ }^{3}$
}

I Waldstrasse 5a, 66999 Hinterweidenthal, Germany 2 Animal Systematics Laboratory, Faculty of Biology, Universitas Gadjah Mada Jl. Teknika Selatan, Sekip Utara Yogyakarta 55281, Indonesia 3 Museum für Naturkunde -Leibniz Institute for Evolution and Biodiversity Science, Invalidenstraße 43, 10115 Berlin, Germany

Corresponding author: Christian Lukhaup (craykeeper@gmx.de)

Academic editor: P. Stoev | Received 21 March 2017 | Accepted 23 March 2017 | Published 4 April 2017

http://zoobank.org/9283383B-CC1F-49DF-B1D2-B81B07150000

Citation: Lukhaup C, Eprilurahman R, Rintelen T (2017) Corrigenda: Cherax warsamsonicus, a new species of crayfish from the Kepala Burung (Vogelkop) peninsula in West Papua, Indonesia (Crustacea, Decapoda, Parastacidae) ZooKeys 660: 151-167. https://doi.org/10.3897/zookeys.660.11847. ZooKeys 665: 147-148. https://doi.org/10.3897/ zookeys.665.12850

It has come to our attention that in the work referenced above Table 1 is incomplete. Furthermore, Figure 7 as printed therein is not the final version of that figure.

The correct versions of both Table 1 and Figure 7 are reproduced here below.

Copyright Christian Lukhaup et al. This is an open access article distributed under the terms of the Creative Commons Attribution License (CC BY 4.0), which permits unrestricted use, distribution, and reproduction in any medium, provided the original author and source are credited. 
Table I. Material studied with GenBank accession numbers.

\begin{tabular}{|c|c|c|c|}
\hline \multirow{2}{*}{ Species/sample } & \multirow{2}{*}{ Location } & \multicolumn{2}{|c|}{ GenBank acc. nos } \\
\hline & & COI & $16 S$ \\
\hline Cherax albertisii & Bensbach River, Papua New Guinea (Queensland Museum) & - & KJ920770 \\
\hline C. boesemani & $\begin{array}{c}\text { Ajamaru Lake, Papua Barat; } 1^{\circ} 17^{\prime} 19.97^{\prime \prime S} \\
132^{\circ} 14^{\prime} 49.14^{\prime \prime E ; ~ J a n u a r y ~} 23,2016\end{array}$ & $\begin{array}{l}\text { KY654084 } \\
\text { KY654085 }\end{array}$ & $\begin{array}{l}\text { KY654089 } \\
\text { KY654090 }\end{array}$ \\
\hline C. holthuisi & Papua Barat & KU821419 & KU821433 \\
\hline C. misolicus & Misool Island, South of Papua Barat (Leiden Museum) & - & KJ920813 \\
\hline C. monticola & Baliem River, Wamena, Papua & $\begin{array}{c}\text { KF649851 } \\
-\end{array}$ & $\begin{array}{l}\text { KF649851 } \\
\text { KJ920818 }\end{array}$ \\
\hline C. paniaicus & Lake Tage, Papua (Field collection) & KJ950528 & KJ920830 \\
\hline C. peknyi & Pet Shop & KU821422 & KU821435 \\
\hline C. pulcher & $\begin{array}{c}\text { Hoa Creek (Teminabuan), Papua Barat; } \\
1^{\circ} 28^{\prime} 32.73^{\prime \prime S}, 132^{\circ} 3^{\prime} 54.94 " E ; \text { January 23, } 2016\end{array}$ & KY654083 & KY654088 \\
\hline C. ,pulcher & Papua Barat (Pet Shop) & $\begin{array}{l}\text { KU821424 } \\
\text { KU821426 }\end{array}$ & $\begin{array}{l}\text { KU821438 } \\
\text { KU821437 }\end{array}$ \\
\hline C. rhynchotus & $\begin{array}{l}\text { Lake Wicheura, Cape York, Queensland } \\
\text { (Queensland Museum) }\end{array}$ & - & KJ920765 \\
\hline C. snowden & $\begin{array}{l}\text { Oinsok (Ainsok River Drainage), Papua Barat; } \\
1^{\circ} 11^{\prime} 40.07^{\prime \prime} S, 131^{\circ} 50^{\prime} 1.14 \text { "E; January 24, } 2016\end{array}$ & KY654082 & KY654087 \\
\hline C. warsamsonicus & $\begin{array}{c}\text { Small tributary to Warsamson River, } \\
0^{\circ} 49^{\prime} 16.62^{\prime \prime} S, 131^{\circ} 23^{\prime} 3.34 \text { "E; January 20, } 2016\end{array}$ & KY654086 & KY654091 \\
\hline Engaeus strictifrons & Crawford River, Victoria, Australia & AF493633 & AF492812 \\
\hline Euastacus bispinosus & Crawford River, Victoria, Australia & AF493634 & AF492813 \\
\hline
\end{tabular}

A $\operatorname{col} \& 16 \mathrm{~s}$

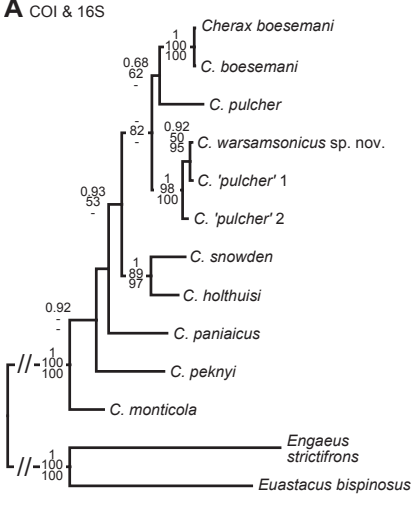

B cOI

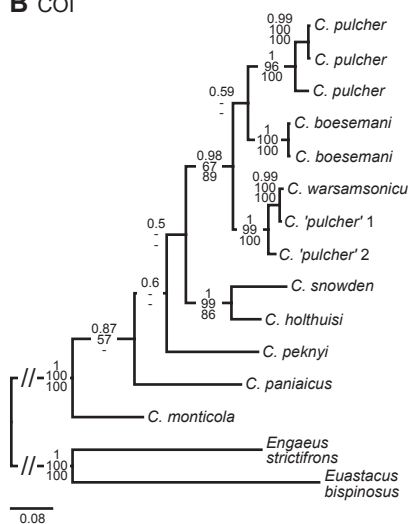

C $16 \mathrm{~S}$

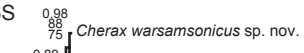

0.98
75 $\overline{0.06}$

Figure 7. Phylogenetic position of Cherax warsamsonicus sp. n. within closely related New Guinean Cherax species, reconstructed by BI analyses of two mitochondrial gene fragments. Number on branches show, from top, Bayesian posterior probabilities and ML/MP bootstrap values. The scale bar indicates the substitution rate. See Table 1 for information on the sequenced specimens. A Topology based on concatenated COI and 16S dataset B Topology based on COI dataset C Topology based on 16S dataset. 